\title{
Hypoglycemia Communication in Primary Care Visits for Patients with Diabetes
}

\author{
Scott J. Pilla, MD, MHS ${ }^{1,2}$, Jenny Park, $B A^{7}$, Jessica L. Schwartz, MD, $M H S^{7}$, \\ Michael C. Albert, MD, FACP ${ }^{1,3}$, Patti L. Ephraim, MPH ${ }^{2,4}$, L. Ebony Boulware, MD, MPH', \\ Nestoras N. Mathioudakis, MD, MHS , Nisa M. Maruthur, MD, MHS ${ }^{1,2,4}$, \\ Mary Catherine Beach, $M D, M P H^{1,2,7}$, and Raquel C. Greer, $M D, M H S^{1,2,4}$
}

\begin{abstract}
'Department of Medicine, Division of General Internal Medicine, The Johns Hopkins University School of Medicine, Baltimore, MD, USA; ${ }^{2}$ Welch Center for Prevention, Epidemiology \& Clinical Research, Baltimore, MD, USA; ${ }^{3}$ Johns Hopkins Community Physicians, Johns Hopkins University, Baltimore, MD, USA; ${ }^{4}$ Department of Epidemiology, The Johns Hopkins Bloomberg School of Public Health, Baltimore, MD, USA; ${ }^{5}$ Division of General Internal Medicine, Duke University, Durham, NC, USA; ${ }^{6}$ Department of Medicine, Division of Endocrinology, Diabetes, \& Metabolism, The Johns Hopkins University School of Medicine, Baltimore, MD, USA; ${ }^{7}$ Department of Health, Behavior \& Society, The Johns Hopkins Bloomberg School of Public Health, Baltimore, MD, USA.
\end{abstract}

BACKGROUND: Hypoglycemia is a common and serious adverse effect of diabetes treatment, especially for patients using insulin or insulin secretagogues. Guidelines recommend that these patients be assessed for interval hypoglycemic events at each clinical encounter and be provided anticipatory guidance for hypoglycemia prevention.

OBJECTIVE: To determine the frequency and content of hypoglycemia communication in primary care visits.

DESIGN: Qualitative study

PARTICIPANTS: We examined 83 primary care visits from one urban health practice representing 8 clinicians and 33 patients using insulin or insulin secretagogues.

APPROACH: Using a directed content analysis approach, we analyzed audio-recorded primary care visits collected as part of the Achieving Blood Pressure Control Together study, a randomized trial of behavioral interventions for hypertension. The coding framework included communication about interval hypoglycemia, defined as discussion of hypoglycemic events or symptoms; the components of hypoglycemia anticipatory guidance in diabetes guidelines; and hypoglycemia unawareness. Hypoglycemia documentation in visit notes was compared to visit transcripts.

KEY RESULTS: Communication about interval hypoglycemia occurred in $24 \%$ of visits, and hypoglycemic events were reported in 16\%. Despite patients voicing fear of hypoglycemia, clinicians rarely assessed hypoglycemia frequency, severity, or its impact on quality of life. Hypoglycemia anticipatory guidance was provided in $21 \%$ of visits which focused on diet and behavior change; clinicians rarely counseled on hypoglycemia treatment or avoidance of driving. Limited discussions of hypoglycemia unawareness occurred in $8 \%$ of visits. Documentation in visit notes had low sensitivity but high specificity for ascertaining interval hypoglycemia communication or hypoglycemic events, compared to visit transcripts.

Prior Presentations None

Received May 14, 2020

Accepted December 2, 2020

Published online January 21, 2021
CONCLUSIONS: In this high hypoglycemia risk population, communication about interval hypoglycemia and counseling for hypoglycemia prevention occurred in a minority of visits. There is a need to support clinicians to more regularly assess their patients' hypoglycemia burden and enhance counseling practices in order to optimize hypoglycemia prevention in primary care.

KEY WORDS: diabetes mellitus; hypoglycemia; primary care; communication; Achieving Blood Pressure Control Together (ACT) study.

J Gen Intern Med 36(6):1533-42

DOI: $10.1007 / \mathrm{s} 11606-020-06385-\mathrm{x}$

(c) Society of General Internal Medicine 2021

\section{INTRODUCTION}

Hypoglycemia is the most common serious adverse event caused by diabetes treatment. ${ }^{1,2}$ Severe hypoglycemia, resulting in neuroglycopenic symptoms requiring assistance from another person, is associated with significant morbidity including vascular events, falls, cognitive impairment, and death. $^{3-10}$ In a recent large survey of adults with diabetes, $12 \%$ reported experiencing severe hypoglycemia in the past year. ${ }^{11}$ Rates of hypoglycemia are higher for older adults, insulin users, people with chronic health conditions, and racial and ethnic minorities. $1,12,13$

Most outpatient diabetes treatment in the USA occurs in primary care offices, and these encounters have a critical role for hypoglycemia prevention. ${ }^{14}$ Diabetes guidelines recommend assessing for interval hypoglycemia at each clinical visit, especially for patients using insulin or insulin secretagogues which cause the majority of hypoglycemia. ${ }^{3,15-18}$ For these patients, guidelines recommend that clinicians routinely provide anticipatory guidance for hypoglycemia prevention, including counseling on situations that may precipitate hypoglycemia, management of hypoglycemic events, and avoidance of driving with hypoglycemia. ${ }^{3,15-18}$ It is also recommended to assess for hypoglycemia unawareness, the 
phenomenon where a patient does not experience the autonomic symptoms of hypoglycemia at low blood glucose levels, which contributes to treatment-related anxiety and a higher risk for severe hypoglycemia. ${ }^{3,15-18}$

Due to the complex nature of hypoglycemia assessment and counseling, high-quality patient-provider communication may be especially important for achieving hypoglycemia prevention. ${ }^{19-25}$ However, we are aware of no prior studies examining hypoglycemia communication in clinical encounters. In this study, we aimed to determine the frequency and content of hypoglycemia assessment and counseling for patients with diabetes in the primary care setting, and to explore potential avenues for improving hypoglycemia communication.

\section{METHODS}

\section{Study Design and Population}

We conducted a qualitative study, with quantitative analyses to provide context, examining participants in the Achieving Blood Pressure Control Together (ACT) study, a randomized trial of hypertension behavioral self-management for blood pressure control. ${ }^{26} \mathrm{ACT}$ included African Americans receiving primary care at an academic community-based primary care practice in Baltimore, MD. Eligible participants were aged $\geq 18$ years, were self-reported African American, had systolic blood pressure $\geq 140 \mathrm{mmHg}$ or diastolic blood pressure $\geq 90 \mathrm{mmHg}$ on two occasions, and were able to speak English. ACT enrolled 159 participants between September 2013 and June 2014. ${ }^{26}$

The ACT intervention included home visits by a community health worker to promote blood pressure selfmanagement in all participants, who were randomized 1:1:1 to receive the following: (1) no additional intervention; (2) "DoMyPart," a training curriculum in shared decision-making about hypertension; or (3) training in problem solving for behavioral self-management. ${ }^{27,28}$ Participants were followed for 12 months for the primary outcome of blood pressure control. All regularly scheduled primary care visits were audio-recorded during the study period. These visits were for routine primary care and had no relationship with the study interventions.

This study included the subset of ACT participants from all study arms who had diabetes mellitus and who were using a sulfonylurea, megltinide, or insulin. Participants, their companions who were present for the visit, and clinicians gave written informed consent to be audio-recorded. The ACT study received local institutional review board approval and is registered with ClinicalTrials.gov (NCT01902719).

\section{Data Collection}

We transcribed verbatim participants' first three audiorecorded primary care visits, which occurred between November 2013 and March 2015. We included a maximum of three visits per participant as an informative sample within the 1year study period. From these transcripts, we abstracted discussions related to diabetes, blood glucose, hypoglycemia, counseling for hypoglycemia prevention, or potential hypoglycemia symptoms according to the Edinburgh Hypoglycemia Symptom Scale. ${ }^{29}$ We abstracted text related to the aforementioned topics from the corresponding visit notes in the electronic health record in order to compare hypoglycemia communication to visit note documentation. We also abstracted the diabetes medications used in the visit; the visit International Classification of Diseases, 9th Revision (ICD-9) codes; the reason for visit (text from the "reason for visit" text box); the patient's most recent hemoglobin $\mathrm{A} 1 \mathrm{c}(\mathrm{HbA} 1 \mathrm{c})$ value prior to the visit (all values were within 6 months); their diabetes subtype; and whether the patient received diabetes care by a specialist or other non-physician healthcare provider during the study period. Other participant characteristics were ascertained by the ACT study using intervieweradministered questionnaires.

\section{Coding of Hypoglycemia Discussions}

Two study team members, both practicing general internists in primary care, independently reviewed the abstracted discussions and corresponding text from visit note documentation using a directed content analysis approach. ${ }^{30}$ We developed an initial coding framework by creating operational definitions of communicative acts relevant to hypoglycemia based on clinical guidelines for diabetes care and consensus of the study team. ${ }^{3,15-18}$ This initial framework included the following: (1) communication about interval hypoglycemia, (2) assessment for hypoglycemia unawareness, and (3) provision of anticipatory guidance for hypoglycemia. Communication about interval hypoglycemia was defined as clinician queries about hypoglycemic events or symptoms that elicited a response by the patient, or patient reports of hypoglycemic events or symptoms that were followed up by the clinician. We did not include in this definition (but ascertained separately) discussions of blood glucose values without mention of hypoglycemia, or patient reports of concerns about normal blood glucose levels being low. Where hypoglycemia communication occurred, we coded who initiated the discussion and its context (e.g., emerging from discussion of diabetes management) and content (hypoglycemic event frequency, severity, and precipitants). Assessment for hypoglycemia unawareness was defined as any discussion of the patient's symptoms (or lack thereof) during hypoglycemic events. Anticipatory guidance for hypoglycemia included any of the following categories: general hypoglycemia counseling (the definition of hypoglycemia, its causes and sequelae, or its relationship to diabetes treatment); behavior change for hypoglycemia prevention (changes in diet, exercise, medication timing, or blood glucose monitoring); treatment of hypoglycemic events (ingesting carbohydrate); and avoidance of driving with hypoglycemia. During coding, the preliminary framework was modified to 
reflect the range of topics that emerged. The coders then compared and discussed their codes, and all differences were reconciled through consensus to yield the final coding framework (Supplementary 1).

\section{Statistical Analysis}

We reported the frequency of communicative acts related to hypoglycemia as the proportion of total visits or of relevant subsets. We compared the characteristics of visits in which communication about interval hypoglycemia occurred, versus did not occur, using unadjusted generalized estimating equations regression with a binomial distribution and unstructured covariance matrix accounting for clustering among patients with repeated visits. We determined the validity of visit note documentation, compared to visit transcripts as the reference standard, by calculating sensitivity, specificity, positive and negative predictive values, and the kappa coefficient. ${ }^{31-33} \mathrm{We}$ also examined whether visit notes included an ICD-9 code for hypoglycemia. ${ }^{34}$

\section{RESULTS}

\section{Patient and Visit Characteristics}

There were 83 included primary care visits representing 33 patients and eight clinicians (seven physicians and one nurse practitioner). At baseline, patients had a mean age of 60.6 years and two-thirds were female (Table 1). All patients had type 2 diabetes except for one with type 1 diabetes, and insulin was used by $61 \%$ of patients.

Characteristics of the included primary care visits suggest that diabetes care was a major focus of the visits (Table 2). All visits except one included a diagnosis code for diabetes, and diabetes was the primary diagnosis in $84 \%$ of visits. The most common reasons for the visit were diabetes, either listed alone (18\% of visits) or with other reasons (25\% of visits), and follow-up (36\% of visits). Visit complexity was high, with over half of visits having six or more coded diagnoses. No visits included a diagnosis code for hypoglycemia.

\section{Communication About Interval Hypoglycemia: Frequency and Content}

Frequency. Communication about interval hypoglycemia occurred in 20 of 83 visits (24\%). Among these 20 visits, the patient indicated that they had one or more hypoglycemic events in 65\% (13/20) (Fig. 1a). Communication about interval hypoglycemia in a visit was not significantly associated with the patient's diabetes treatment, glycemic control, the reason for visit, visit diagnoses, or the number of visits during the study period (Table 2). Of the 33 patients, 14 (42\%) had communication about interval hypoglycemia at any visit during
Table 1 Patient Characteristics at Study Baseline

\begin{tabular}{|c|c|}
\hline Characteristic* & $\begin{array}{l}\text { Finding }{ }^{\dagger}(N= \\
\text { 33) }\end{array}$ \\
\hline Age, mean (SD), years & $60.6(9.8)$ \\
\hline Female gender & $22(66.7)$ \\
\hline Type 2 diabetes & $32(97.0)$ \\
\hline \multicolumn{2}{|l|}{ Hemoglobin Alc category } \\
\hline$<6.5 \%$ & $3(9.1)$ \\
\hline $6.5-6.9 \%$ & $8(24.2)$ \\
\hline $7.0-7.9 \%$ & $6(18.2)$ \\
\hline $8.0-8.9 \%$ & $2(6.1)$ \\
\hline$\geq 9.0 \%$ & $14(42.4)$ \\
\hline Any insulin use & $20(60.6)$ \\
\hline Long acting insulin use & $18(54.6)$ \\
\hline Rapid acting insulin use & $7(21.2)$ \\
\hline Sliding scale insulin use & $1(3.0)$ \\
\hline Sulfonylurea use & $15(45.5)$ \\
\hline Both sulfonylurea and insulin use & $2(6.1)$ \\
\hline Meglitinide use & \\
\hline Metformin use & $17(51.5)$ \\
\hline $\begin{array}{l}\text { Diabetes medication use other than metformin, } \\
\text { sulfonylurea, or insulin }\end{array}$ & $1(3.0)$ \\
\hline $\begin{array}{l}\text { Received diabetes care by a specialist or other non- } \\
\text { physician provider }\end{array}$ & $1(3.0)$ \\
\hline Chronic kidney disease & $8(24.2)$ \\
\hline \multirow{2}{*}{\multicolumn{2}{|c|}{$\begin{array}{l}\text { Highest level of education } \\
\text { Hign }\end{array}$}} \\
\hline & \\
\hline Less than high school & $15(45.5)$ \\
\hline High school diploma or equivalency & $16(48.5)$ \\
\hline Some college (associate degree) & $1(3.0)$ \\
\hline Do not know & $1(3.0)$ \\
\hline \multicolumn{2}{|l|}{ Yearly family income } \\
\hline$<\$ 5000$ & $6(18.2)$ \\
\hline$\$ 5000-\$ 20,000$ & $9(27.3)$ \\
\hline$\$ 20,000-\$ 40,000$ & $7(21.2)$ \\
\hline$\$ 40,000-\$ 60,000$ & $4(12.1)$ \\
\hline$>\$ 60,000$ & $3(9.1)$ \\
\hline Do not know or refuse & $4(12.1)$ \\
\hline \multicolumn{2}{|l|}{ Health insurance } \\
\hline Private health insurance & $9(27.3)$ \\
\hline Medicare only & $16(48.5)$ \\
\hline Medicaid only & $2(6.1)$ \\
\hline Medicare and Medicaid & $1(3.0)$ \\
\hline Other insurance & $3(9.1)$ \\
\hline Uninsured & $2(6.1)$ \\
\hline $\begin{array}{l}\text { Total number of primary care visits per participant } \\
\text { during study period, median (IQR) }\end{array}$ & $3(2)$ \\
\hline \multicolumn{2}{|c|}{ Number of primary care visits analyzed per participant } \\
\hline One visit & $6(18.2)$ \\
\hline Two visits & $3(9.1)$ \\
\hline Three visits & $24(72.7)$ \\
\hline
\end{tabular}

*Characteristics reported are from baseline study data except for hemoglobin Alc which is the most recent value before the first participants' first included primary care visit, and medications which are those used at their first primary care visit

tData are presented as number (percentage) of participants unless otherwise indicated

the study. Of the eight providers, hypoglycemia communication occurred in a minority of visits (9 to 23\%) for five providers and a majority of visits (56 to $63 \%$ ) for two providers; one provider had only one included visit and hypoglycemia was not discussed.

While assessment for hypoglycemia occurred in a minority of visits, there were an additional 25 visits $(30 \%)$ in which home blood glucose values were discussed without mentioning hypoglycemia. The level of detail of these discussions was inconsistent, ranging from very brief (e.g., Clinician: What is it running at home? Patient: It was 109. Clinician: Terrific.), to an in-depth review of the patient's glucometer readings or home glucose log. 
Table 2 Characteristics of Primary Care Visits, Overall and Stratified by Whether Communication About Interval Hypoglycemia Occurred in the Visit

\begin{tabular}{|c|c|c|c|}
\hline \multirow[t]{2}{*}{ Characteristic $^{*}$} & \multicolumn{3}{|c|}{ Finding $^{\dagger}$} \\
\hline & $\begin{array}{l}\text { All } \\
\text { visits } \\
(N= \\
83)\end{array}$ & $\begin{array}{l}\text { Interval } \\
\text { hypoglycemia } \\
\text { not discussed } \\
(N=63)\end{array}$ & $\begin{array}{l}\text { Interval } \\
\text { hypoglycemia } \\
\text { discussed }(N= \\
20)\end{array}$ \\
\hline \multicolumn{4}{|l|}{ Reason for visit ${ }^{+}$} \\
\hline Diabetes only & $\begin{array}{l}15 \\
(18.1)\end{array}$ & $9(14.3)$ & $6(30.0)$ \\
\hline $\begin{array}{l}\text { Diabetes and } \\
\text { other reasons }\end{array}$ & $\begin{array}{l}21 \\
(25.3)\end{array}$ & $15(23.8)$ & $6(30.0)$ \\
\hline Follow-up & $\begin{array}{l}30 \\
(36.1)\end{array}$ & $26(41.3)$ & $4(20.0)$ \\
\hline All others & $\begin{array}{l}17 \\
(20.5)\end{array}$ & $13(20.6)$ & $4(20.0)$ \\
\hline $\begin{array}{l}\text { The visit included } \\
\text { a diagnosis code } \\
\text { for diabetes } \\
\S\end{array}$ & $\begin{array}{l}82 \\
(98.8)\end{array}$ & $62(98.4)$ & $20(100.0)$ \\
\hline $\begin{array}{l}\text { Diabetes was the } \\
\text { primary visit } \\
\text { diagnosis }\end{array}$ & $\begin{array}{l}70 \\
(84.3)\end{array}$ & $53(84.1)$ & $17(85.0)$ \\
\hline $\begin{array}{l}\text { Diabetes was } \\
\text { listed as a problem } \\
\text { in the visit plan }\end{array}$ & $\begin{array}{l}82 \\
(98.8)\end{array}$ & $62(98.4)$ & $20(100.0)$ \\
\hline \multicolumn{4}{|c|}{ Total number of diagnosis codes for the visit } \\
\hline $2-3$ & $\begin{array}{l}11 \\
(13.3)\end{array}$ & $10(15.9)$ & $1(5.0)$ \\
\hline $4-5$ & $\begin{array}{l}28 \\
(33.7)\end{array}$ & $21(33.3)$ & $7(35.0)$ \\
\hline$\geq 6$ & $\begin{array}{l}44 \\
(53.0)\end{array}$ & $32(50.8)$ & $12(60.0)$ \\
\hline \multicolumn{4}{|c|}{ Patient's diabetes subtype } \\
\hline Type 1 & $3(3.6)$ & $3(4.8)$ & 0 \\
\hline Type 2 & $\begin{array}{l}80 \\
(96.4)\end{array}$ & $60(95.2)$ & $20(100.0)$ \\
\hline \multicolumn{4}{|c|}{ Patient's most recent hemoglobin A1c prior to visit, categories } \\
\hline$<6.5 \%$ & $8(9.6)$ & $4(6.4)$ & $4(20.0)$ \\
\hline $6.5-6.9 \%$ & $\begin{array}{l}15 \\
(18.1)\end{array}$ & $9(14.3)$ & $6(30.0)$ \\
\hline $7.0-7.9 \%$ & $\begin{array}{l}21 \\
(25.3)\end{array}$ & $18(28.6)$ & $3(15.0)$ \\
\hline $8.0-8.9 \%$ & $7(8.4)$ & $5(7.9)$ & $2(10.0)$ \\
\hline$\geq 9.0 \%$ & $\begin{array}{l}32 \\
(38.6)\end{array}$ & $27(42.9)$ & $5(25.0)$ \\
\hline $\begin{array}{l}\text { Any insulin use at } \\
\text { time of visit }\end{array}$ & $\begin{array}{l}54 \\
(65.1)\end{array}$ & $41(65.1)$ & $13(65.0)$ \\
\hline $\begin{array}{l}\text { Rapid acting } \\
\text { insulin use at time } \\
\text { of visit }\end{array}$ & $\begin{array}{l}23 \\
(27.7)\end{array}$ & $19(30.2)$ & $4(20.0)$ \\
\hline \multicolumn{4}{|c|}{ Number of visits during study period" } \\
\hline $1-3$ visits & $\begin{array}{l}43 \\
(51.8)\end{array}$ & $32(50.8)$ & $11(55.0)$ \\
\hline $4-5$ visits & $\begin{array}{l}23 \\
(27.7)\end{array}$ & $18(28.6)$ & $5(25.0)$ \\
\hline$>5$ visits & $\begin{array}{l}17 \\
(20.5)\end{array}$ & $13(20.6)$ & $4(20.0)$ \\
\hline
\end{tabular}

*All $p$ values comparing visits with vs. without interval hypoglycemia communication were $>0.05$ using unadjusted generalized estimating equations regression accounting for patient clustering

$\not$ The text listed in the "Reason for Visit" text box of the electronic health record

${ }^{\S}$ Diabetes ICD-9 codes were 250.xx. No visits included a diagnosis code for hypoglycemia (ICD-9 codes 251.0, 251.1, 251.2, 270.3, or 962.3)

"The total number of primary care visits, regardless of whether the visit was analyzed for this study

Notably, patients sometimes referred to their blood glucose as "low" without necessarily meaning hypoglycemia, and these instances were not counted as discussions about interval hypoglycemia.
Patient: In the morning it's low, but at night it's higher. Clinician: Uh-huh. Okay. How low it is in the morning?

Patient: Oh, not real low, like 123, 137, something like that.There were also four visits where the patient reported concerns about their blood glucose values in the normal range being too low, and similarly these were not counted as discussions about interval hypoglycemia.

Patient: My sugar was low today.

Clinician: No, that's normal.

Patient: Ninety-six?

Clinician: Ninety-six is normal.

Patient: That ain't low?

Clinician: No.

Content. In the 20 visits where communication about interval hypoglycemia occurred (Table 3), the discussion was most often initiated by the clinician (14/20 visits, $70 \%)$ who typically asked about hypoglycemic events directly using the phrase "low blood sugar" or referred to blood glucose values that were "too low" or "really low." In $6 / 20$ visits (30\%), the patient reported hypoglycemic events unprompted. Hypoglycemia communication most often emerged from the context of discussions of glucose readings $(10 / 20,50 \%)$ or diabetes management $(6 / 20,30 \%)$.

In the 13 visits where the patient indicated that they had hypoglycemia (Fig. 1a, Table 3), most discussions (10/13, $76 \%$ ) focused on what precipitated specific hypoglycemic events, such as changes in diet or medications. About half $(6 / 13,46 \%)$ had a limited assessment of hypoglycemia severity by asking the lowest glucose reading at the time of the event, but never whether the patient needed help from another person or used emergency medical services. Clinicians rarely explored the frequency of hypoglycemia, which was covered in only $1 / 13(8 \%)$ visits. Hypoglycemia unawareness was discussed in $7 / 13$ visits $(54 \%)$.

In three visits in which patients reported hypoglycemic events, they also expressed that these events were frightening or concerning. Clinicians responded to these patient statements by asking goal-directed questions without acknowledging or exploring the emotions that the patients expressed.

Patient: Just - it's just so frightening, uh, when it goes down so low, ugh.

Clinician: How low? What is the lowest reading you got?

Patient: I've gotten, um, a 56.

Clinician: Uh-huh.

Patient: One time, I got, um, uh, I think it was a 40something.

Clinician: When was that? 

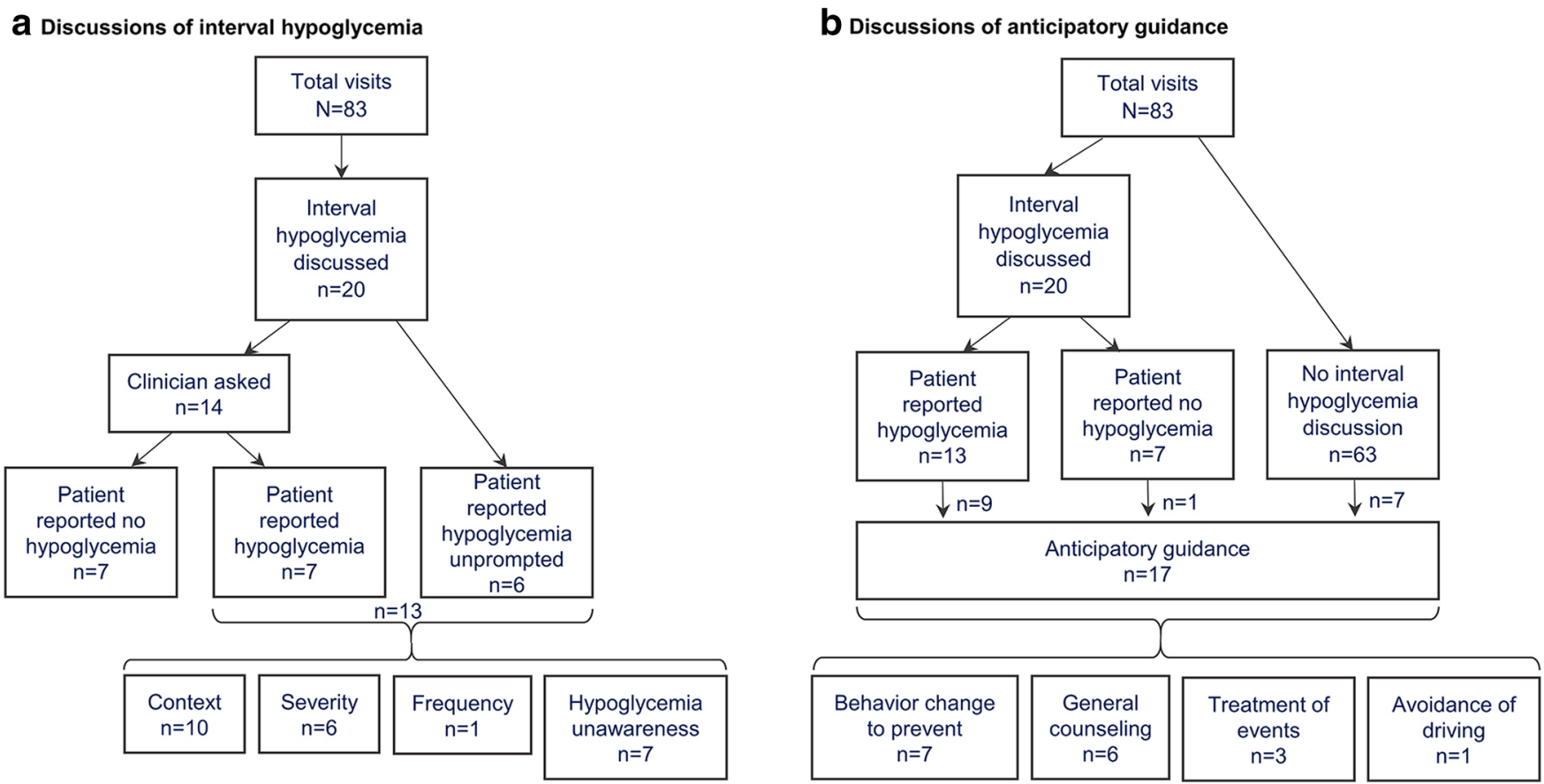

Figure 1 Frequency and content of discussions of interval hypoglycemia and anticipatory guidance for hypoglycemia prevention. Interval hypoglycemia discussions were defined as clinician queries about hypoglycemic events or symptoms that elicited a response by the patient, or patient reports of hypoglycemic events or symptoms that were followed up by the clinician. Discussions of hypoglycemia unawareness were any discussion of the patient's symptoms (or lack thereof) during hypoglycemic events. Anticipatory guidance for hypoglycemia was categorized as behavior change to prevent hypoglycemia (changes in diet, exercise, medication timing, or blood glucose monitoring), general hypoglycemia counseling (the definition of hypoglycemia, its causes and sequelae, or its relationship to diabetes treatment), treatment of hypoglycemic events (ingesting carbohydrate), and avoidance of driving with hypoglycemia. a Discussions of interval hypoglycemia. b Discussions of anticipatory guidance.

\section{Anticipatory Guidance About Hypoglycemia}

Anticipatory guidance about hypoglycemia (Fig. 1b, Table 4) was discussed in $17 / 83$ visits $(20 \%)$. Fewer than half of discussions $(7 / 17,41 \%)$ addressed behavior change to prevent future episodes, which focused on avoiding hypoglycemia by following a regular schedule of meals and medication administration. In 6/17 discussions (35\%), clinicians gave general hypoglycemia counseling which focused on explaining the relationship between hypoglycemia and diabetes treatment. Few discussions addressed how to treat hypoglycemic events when they occur $(3 / 17,18 \%)$, and avoidance of driving $(1 / 17$, $6 \%$ ). Clinicians were more likely to provide anticipatory guidance when the patient reported interval hypoglycemia $(9 / 13$, $69 \%$ ), and less likely when the patient denied hypoglycemia $(1 / 7,14 \%)$ or there was no discussion of interval hypoglycemia $(7 / 63,11 \%)$. Of the 33 patients, $12(36 \%)$ received hypoglycemia anticipatory guidance in at least one of their visits. Of the eight providers, four frequently provided anticipatory guidance (33 to $50 \%$ of visits) and four rarely provided anticipatory guidance (0 to $18 \%$ of visits).

\section{Comparison of Visit Transcripts to Documentation in Visit Notes}

Using visit transcripts as the reference standard, we determined the validity of ascertaining discussions of interval hypoglycemia, or the occurrence of hypoglycemic events, from visit note documentation (Table 5). For either outcome, visit notes had limited sensitivity but high specificity; Kappa was 0.50 and 0.73 , respectively. A variety of language was used to indicate hypoglycemia in visit note documentation (Supplementary 1).

\section{DISCUSSION}

In this population of patients with diabetes at high risk for hypoglycemia from one primary care practice, we found that communication about interval hypoglycemia occurred in approximately one in four visits, and discussions of anticipatory guidance for hypoglycemia and hypoglycemia unawareness occurred even less frequently. Additionally, we identified three areas where hypoglycemia communication may be suboptimal: (1) a lack of assessment of the frequency or severity of hypoglycemic events; (2) a lack of counseling on hypoglycemia treatment or avoidance of driving; and (3) a lack of exploration of the emotional impact of hypoglycemia, despite patients voicing these concerns.

We identified no previous studies examining hypoglycemia communication in clinical encounters. A prior study of 28 audio-recorded primary care visits for diabetes found that all visits included discussion of diabetes self-care activities; hypoglycemia prevention practices were not examined. ${ }^{35} \mathrm{~A}$ recent study found that documentation of hypoglycemia 
Table 3 Representative Quotes for the Content and Level of Detail of Communication About Interval Hypoglycemia

\begin{tabular}{ll}
\hline \hline Communicative act & $\begin{array}{l}\text { Number of } \\
\text { visits }\end{array}$ \\
Representative quotes
\end{tabular}

How the discussion of interval hypoglycemia was initiated

(the 20 visits with discussion of interval hypoglycemia were categorized into one of these mutually exclusive groups)

The clinician asked about hypoglycemic events 12 directly.

The clinician asked about hypoglycemia symptoms 2 without labeling them as hypoglycemia.

The patient reported one or more hypoglycemic events unprompted.

The context from which discussion of interval hypoglycemia emerged (the 20 visits with discussion of interval hypoglycemia were categorized

The topic emerged from discussion of home or in- 10 office blood glucose readings.

(a)

Clinician: And how do you feel when you have those readings?

Patient: Okay.

Clinician: Okay? No jitteriness, no nervousness, anything?

Patient: Unh-unh.

Patient: I just did not have an appetite, and I did not know what I wanted to eat. I ate dinner around 1:30.

Clinician: Dinner? At dinner?

Patient: No, at 1:30. I had not eaten any breakfast, any lunch. But then, my body felt like I was shaking. Like...

Clinician: Yeah. That's all your medications - diabetes medicines. That means it kicked in.
The topic emerged from discussion of diabetes management.
6

2 symptoms or concerns.

Clinician: Okay. How's your blood sugars running at home?

Patient: Oh -

Clinician: Do you have your book with you? Okay, so, mostly, they are ranging pretty well?

Patient: Mm-hmm.

Clinician: So you had one low one down to 51, I see here. Do you know why it dropped?

Clinician: It's a pre-meal. That's mean you need to take it before meal.

Patient: Right.

Clinician: If you take it after, not good. That will drop your blood pressure your blood sugar.

Patient: Yeah, I have not been, um - today, I had to eat while I was in dialysis because, um, it was running low and I just had to eat something.

Clinician: What day were you at Patient First?

Patient: Uh, Saturday and then I went back yesterday.

Clinician: So back to see them twice. Did they -

Patient: Yeah, because the cough medicine they had gave me to take was making my sugar drop low.

The clinician asked about hypoglycemia without $\quad 2$ context, as in a review of systems.

Clinician: Swelling in your feet? Your sugar does not drop too much. Do you check it at home?

Patient: Mm-hmm

The content and level of detail of discussions of hypoglycemic events that occurred

(the 13 visits where hypoglycemia was reported were categorized into one or more of these groups)

The context around a specific hypoglycemic event 10 was explored.

Clinician: Have you had any episodes of your sugar going down too low where you get shaky or sweaty or nervous?

Patient: One time.

Clinician: When was that?

Patient: That was about three - three or four - maybe a month ago. A month ago.

Clinician: Was that when you took that extra insulin?

Patient: No. Yes, yes.

Clinician: It was when your sugar got too high because you drank the Pepsi? Patient: Right.

Clinician: How much extra insulin did you take?

The severity of the hypoglycemic event(s) was discussed.

The frequency of hypoglycemic events was discussed.

Hypoglycemia unawareness was discussed.

The clinician acknowledged the hypoglycemic event without probing for further details.
6

Patient: Just - it's just so frightening, uh, when it goes down so low, ugh. Clinician: How low? What is the lowest reading you got?

Patient: I've gotten, um, a 56.

Clinician: When was the last time you saw a low like below? You cannot

$7 \quad$ remember. We'll look through your meter. you remember what was going on then. That was more like a week ago.

Where do you start to feel low? Do you feel low at 70 ?

Patient: Well yeah, around 70 .

3 Patient: Today, I had to eat while I was in dialysis because, um, it was running low and I just had to eat something.

Clinician: And that, that's the problem, you know? It's running low. I know you were afraid for, um, it to be low and the problem with that - and I think we, we have a discussion last visit - that if you - the problem, you are not taking the insulin the correct way. assessment in visit note text occurred in $38 \%$ of primary care visits and $69 \%$ of endocrinology visits for patients using insulin or sulfonylureas at a single center. ${ }^{36}$ Low rates of discussion of interval hypoglycemia observed here may be due to the particularly high medical complexity of the study population. Primary care providers are often required to prioritize competing demands in diabetes visits, especially for patients with multiple chronic conditions, yet these same 
Table 4 Representative Quotes for Anticipatory Guidance About Hypoglycemia

\begin{tabular}{|c|c|c|}
\hline Communicative act & $\begin{array}{l}\text { Number of } \\
\text { visits }\end{array}$ & Representative quotes \\
\hline $\begin{array}{l}\text { The clinician counseled on prevention of } \\
\text { hypoglycemia through behavior change. }\end{array}$ & 7 & $\begin{array}{l}\text { Clinician: Now remember, Glipizide is not very forgiving, so you cannot miss any } \\
\text { meals or - } \\
\text { Patient: What you mean? } \\
\text { Clinician: - skip a meal. Well, Metformin is nice because it raises your sugar from } \\
\text { high to normal, but Glipizide can raise it either from high to too low, so you have } \\
\text { to make sure you do not skip a meal. Okay? } \\
\text { Patient: Okay. }\end{array}$ \\
\hline $\begin{array}{l}\text { The clinician provided general counseling } \\
\text { around hypoglycemia. }\end{array}$ & 6 & $\begin{array}{l}\text { Patient: Is it, um, which is the - the most dangerous, too low or too high, right? } \\
\text { Clinician: They both can be dangerous, right, but too low can be dangerous really } \\
\text { quickly. Too high in the long term causes problems, right, but - but if your sugar } \\
\text { is too low, you could - you could get very sick or even die if your sugar was too } \\
\text { low. So we do have to take the lows just as seriously as we take the highs. }\end{array}$ \\
\hline $\begin{array}{l}\text { The clinician counseled on the treatment of } \\
\text { hypoglycemic events that do occur. }\end{array}$ & 3 & $\begin{array}{l}\text { Clinician: Well, what we recommend is that you, you take in something that's } \\
\text { gonna bring your sugar up quickly, so that's why people usually carry the candy } \\
\text { or the glucose tablets or - } \\
\text { Patient: Candy } \\
\text { Clinician: Orange juice. } \\
\text { Patient: Yeah, the juice. Yeah, okay. }\end{array}$ \\
\hline $\begin{array}{l}\text { The clinician counseled on avoidance of driving } \\
\text { with hypoglycemia. }\end{array}$ & 1 & $\begin{array}{l}\text { Clinician: You make sure you check your sugars and stay on your eating schedule } \\
\text { with that driving because we do not want your blood sugar to drop while you are } \\
\text { driving. You feel it when it's low, right? }\end{array}$ \\
\hline
\end{tabular}

The 17 visits where anticipatory guidance about hypoglycemia was discussed were categorized into one or more of the groups shown

patients are also at the highest risk for hypoglycemia. ${ }^{1,12,13,37}$ Participants in this study were all African Americans who have the highest rates of severe hypoglycemia of all racial and ethnic groups, and thus have a greater need for hypoglycemia prevention. $^{12,13}$ These findings suggest the need to support physicians by implementing care systems that routinely assess for hypoglycemia, such as a hypoglycemia patient questionnaire, and expand care teams beyond the primary care physician to help provide education and guidance. ${ }^{3}$

We used a stringent definition of communication about interval hypoglycemia which excluded a substantial minority of visits with discussion of only the patient's home blood glucose values. Review of blood glucose values alone is likely to miss many hypoglycemic events as adherence to glucose self-monitoring practices is low, and clinicians in this study often performed only a very brief review. ${ }^{38-40}$ Review of home glucose values did seem to serve as a prompt for hypoglycemia discussions, although hypoglycemia discussions occurred in less than half of visits in which home glucose readings were reviewed.

When a hypoglycemic event was reported, clinicians focused on determining the cause of the event while rarely assessing details of hypoglycemia frequency or severity. This finding was part of a larger pattern in which physicians did not assess the patients' overall burden of hypoglycemia, its emotional impact, or its effect on the patient's quality of life. It is possible that physicians did not explore these details because they felt that knowledge of a single hypoglycemic event was enough to inform their clinical decision-making, or the high number of concomitant medical issues limited their time. Regardless, this represents an important missed opportunity as fear of hypoglycemia can be a substantial burden on patients and their caregivers, and leads to worse adherence and glycemic control. ${ }^{41-43}$ Further, patients with diabetes prioritize addressing symptomatic concerns in complex visits and rate the risk for adverse drug events as the most important factor for choosing a glycemic target. ${ }^{44-48}$

The anticipatory guidance for hypoglycemia prevention provided by clinicians in this study was generally consistent with guidelines, although incomplete. Areas that were frequently omitted were treatment of hypoglycemic events and avoidance of driving with hypoglycemia. Clinicians also rarely assessed for hypoglycemia unawareness, a potentially modifiable hypoglycemia risk factor. ${ }^{49-52}$ Standardized

Table 5 Validity of Ascertaining Discussion of Interval Hypoglycemia or Hypoglycemic Events from Visit Note Documentation, Compared to Visit Audio Transcripts (Reference Standard)

\begin{tabular}{|c|c|c|c|c|c|}
\hline Outcome & $\begin{array}{l}\text { Sensitivity } \\
\text { (95\% CI) }\end{array}$ & $\begin{array}{l}\text { Specificity } \\
\text { (95\% CI) }\end{array}$ & $\begin{array}{l}\text { Positive predictive value } \\
(95 \% \text { CI) }\end{array}$ & $\begin{array}{l}\text { Negative predictive value } \\
(95 \% \text { CI })\end{array}$ & Kappa \\
\hline $\begin{array}{l}\text { Communication about interval } \\
\text { hypoglycemia occurred }\end{array}$ & $\begin{array}{l}60.0 \% \\
(36.1-80.9)\end{array}$ & $\begin{array}{l}88.9 \% \\
(78.4-95.4)\end{array}$ & $\begin{array}{l}63.2 \% \\
(38.4-83.7)\end{array}$ & $\begin{array}{l}87.5 \% \\
(76.8-94.4)\end{array}$ & 0.50 \\
\hline $\begin{array}{l}\text { The patient had one or more } \\
\text { hypoglycemic events }\end{array}$ & $\begin{array}{l}61.5 \% \\
(31.6-86.1)\end{array}$ & $\begin{array}{l}100.0 \%(94.9- \\
100.0)\end{array}$ & $\begin{array}{l}100.0 \% \\
(63.1-100.0)\end{array}$ & $\begin{array}{l}93.3 \% \\
(85.1-97.8)\end{array}$ & 0.73 \\
\hline
\end{tabular}

The cells of the $2 \times 2$ table representing whether discussion of interval hypoglycemia occurred (columns) and was documented in visit notes (rows) are, across rows from upper left to lower right, the following: 12 (true positive), 7 (false positive), 8 (false negative), 56 (true negative). The cells of the $2 \times 2$ table representing whether one or more hypoglycemic events were reported (columns) and was documented in visit notes (rows) are, across rows from upper left to lower right, the following: 8 (true positive), 0 (false positive), 5 (false negative), 70 (true negative) 
questionnaires and education materials for patients may be needed to fill these gaps. 3,53

Clinicians used the language "low blood sugar" to ask about hypoglycemic events, and our findings suggest that there is some confusion about this terminology. We reviewed several conversations in which patients used "low" as a synonym for "good" with respect to glucose, and others in which patients expressed concern about normal glucose values being too low. More research is needed to examine patients' understanding of the language around hypoglycemia.

Comparing visit note documentation to corresponding transcripts revealed that approximately $40 \%$ of communication about interval hypoglycemia and hypoglycemic events was not documented. Therefore, ascertaining hypoglycemic events from electronic health records, e.g., with natural language processing tools, may miss a substantial proportion of events. ${ }^{54-56}$ Diagnosis codes are often used to ascertain hypoglycemic events; no visits in our study included an ICD-9 code for hypoglycemia highlighting the low sensitivity of this measure. ${ }^{5,12,57}$ Further, increasing hypoglycemia documentation may be important to cue assessment for hypoglycemia at subsequent visits or to other providers. ${ }^{58}$

This study has several limitations. Data are derived from a single clinical site with a select population of medically complex patients who are not generalizable to all adults with diabetes, but do represent an important subset with high hypoglycemia risk. Further, participants were sampled from a clinical trial population who may have differences in medical care from the general population. The small sample size limited our ability to examine associations between patient characteristics and hypoglycemia assessment, which should be examined in larger cohorts. Nonetheless, this report is the first analysis of hypoglycemia communication in primary care and provides needed insight into how communication can be improved, especially among high-risk groups.

In conclusion, communication around hypoglycemia may be suboptimal in primary care practices treating patients with diabetes at high hypoglycemia risk. There is a need to implement strategies to support primary care clinicians to routinely assess and counsel for hypoglycemia, and promote communication around the global impact of hypoglycemia on the patient's health and quality of life.

Supplementary Information The online version contains supplementary material available at https://doi.org/10.1007/s11606-02006385- $x$.

Acknowledgments: Contributors: The ACT Study team consists of members from Duke University, Durham, NC (L. Ebony Boulware); members from the Johns Hopkins University, Baltimore, MD (Hanan Aboumatar, Michael Albert, Jessica Ameling, Lee Bone, Kathryn Carson, Jeanne Charlston, Lisa Cooper, Deidra Crews, Patti Ephraim, Peter Fagan, Debra Gayles, Raquel Greer, Kimberly Gudzune, Haera Han, Felicia Hill-Briggs, David Levine, LaPricia Lewis-Boyer, Richard Matens, Linda Mobula, Debra Roter, Hema Ramamurthi, Valerie Sneed, Rachel Thornton, Jennifer Wolff); and members of the Johns
Hopkins Center to Eliminate Cardiovascular Health Disparities Community Advisory Board (Debra Hickman, Leon Purnell, Michelle Simmons, Annette Fisher); the University of Rochester, Rochester, NY (Gary Nohornha); Rush University (Stephanie Fitzpatrick); the University of Texas, Austin, TX (Miyong Kim); the Unviversity of Maryland, Baltimore, MD (Jeffrey Barbers); and the Brooklyn Hospital Center, Brooklyn, NY (Tanyka Sam).

Corresponding Author: Scott J. Pilla, MD, MHS; Welch Center for Prevention, Epidemiology \& Clinical Research, Baltimore, MD, USA (e-mail: spilla1@jhmi.edu).

Funding Dr. Pilla was supported by the Johns Hopkins KL2 Clinical Research Scholars Program (KL2TR003099). The ACT study was supported by the National Heart, Lung, and Blood Institute (NHLBI) of the National Institutes of Health (1P50HL105187).

\section{Compliance with Ethical Standards:}

Conflict of Interest: The authors declare that they do not have a conflict of interest.

\section{REFERENCES}

1. Lipska KJ, Yao X, Herrin J, McCoy RG, Ross JS, Steinman MA, et al. Trends in Drug Utilization, Glycemic Control, and Rates of Severe Hypoglycemia, 2006-2013. Diabetes Care. 2017;40(4):468-75. https:// doi.org/10.2337/dc16-0985.

2. 9. Pharmacologic Approaches to Glycemic Treatment: Standards of Medical Care in Diabetes-2020. Diabetes Care. 2020;43(Supplement 1):S98-S110. https://doi.org/10.2337/dc20-S009.

3. Seaquist ER, Anderson J, Childs B, Cryer P, Dagogo-Jack S, Fish L, et al. Hypoglycemia and diabetes: a report of a workgroup of the American Diabetes Association and the Endocrine Society. Diabetes Care. 2013;36(5):1384-95. https://doi.org/10.2337/dc12-2480.

4. Budnitz DS, Lovegrove MC, Shehab N, Richards CL. Emergency hospitalizations for adverse drug events in older Americans. N Engl J Med. 2011;365(21):2002-12. https://doi.org/10.1056/ NEJMsal 103053.

5. Lipska KJ, Ross JS, Wang Y, Inzucchi SE, Minges K, Karter AJ, et al. National trends in US hospital admissions for hyperglycemia and hypoglycemia among Medicare beneficiaries, 1999 to 2011. JAMA Intern Med. 2014;174(7):1116-24. https://doi.org/10.1001/jamainternmed. 2014.1824.

6. Zoungas S, Patel A, Chalmers J, de Galan BE, Li Q, Billot L, et al. Severe hypoglycemia and risks of vascular events and death. N Engl J Med. 2010;363(15):1410-8. https://doi.org/10.1056/NEJMoa1003795.

7. Signorovitch JE, Macaulay D, Diener M, Yan Y, Wu EQ, Gruenberger JB, et al. Hypoglycaemia and accident risk in people with type 2 diabetes mellitus treated with non-insulin antidiabetes drugs. Diabetes Obes Metab. 2013;15(4):335-41. https://doi.org/10.1111/dom.12031.

8. Whitmer RA, Karter AJ, Yaffe K, Quesenberry CP, Jr., Selby JV. Hypoglycemic episodes and risk of dementia in older patients with type 2 diabetes mellitus. JAMA. 2009;301(15):1565-72. https://doi.org/10. 1001/jama.2009.460.

9. Bonds DE, Zaccaro DJ, Karter AJ, Selby JV, Saad M, Goff DC, Jr. Ethnic and racial differences in diabetes care: The Insulin Resistance Atherosclerosis Study. Diabetes Care. 2003;26(4):1040-6.

10. McCoy RG, Van Houten HK, Ziegenfuss JY, Shah ND, Wermers RA, Smith SA. Increased mortality of patients with diabetes reporting severe hypoglycemia. Diabetes Care. 2012;35(9):1897-901. https://doi.org/10. 2337/dc11-2054.

11. Karter AJ, Moffet HH, Liu JY, Lipska KJ. Surveillance of HypoglycemiaLimitations of Emergency Department and Hospital Utilization Data. JAMA Intern Med. 2018;178(7):987-8. https://doi.org/10.1001/ jamainternmed.2018.1014.

12. Misra-Hebert AD, Pantalone KM, Ji X, Milinovich A, Dey T, Chagin KM, et al. Patient Characteristics Associated With Severe Hypoglycemia in a Type 2 Diabetes Cohort in a Large, Integrated Health Care System From 2006 to 2015. Diabetes Care. 2018;41(6):1164-71. https://doi.org/ $10.2337 / \mathrm{dc} 17-1834$ 
13. Bloomfield HE, Greer N, Newman D, MacDonald R, Carlyle $\mathbf{M}$, Fitzgerald P, et al. Predictors and Consequences of Severe Hypoglycemia in Adults with Diabetes - A Systematic Review of the Evidence. Washington, DC; 2012.

14. Pilla SJ, Segal JB, Maruthur NM. Primary Care Provides the Majority of Outpatient Care for Patients with Diabetes in the US: NAMCS 20092015. J Gen Intern Med. 2019;34(7):1089-91. https://doi.org/10.1007/ s11606-019-04843-9.

15. Conlin PR, Colburn J, Aron D, Pries RM, Tschanz MP, Pogach L. Synopsis of the 2017 U.S. Department of Veterans Affairs/U.S. Department of Defense Clinical Practice Guideline: Management of Type 2 Diabetes Mellitus. Ann Intern Med. 2017;167(9):655-63. https://doi.org/ 10.7326/M17-1362.

16. LeRoith D, Biessels GJ, Braithwaite SS, Casanueva FF, Draznin B, Halter JB, et al. Treatment of Diabetes in Older Adults: An Endocrine Society* Clinical Practice Guideline. J Clin Endocrinol Metab. 2019. https://doi.org/10.1210/jc.2019-00198.

17. 4. Comprehensive Medical Evaluation and Assessment of Comorbidities: Standards of Medical Care in Diabetes-2020. Diabetes Care. 2020;43(Supplement 1):S37-S47. https://doi.org/10.2337/dc20-S004.

18. 6. Glycemic Targets: Standards of Medical Care in Diabetes-2020. Diabetes Care. 2020;43(Supplement 1):S66-S76. https://doi.org/10. 2337/dc20-S006

19. Bundesmann R, Kaplowitz SA. Provider communication and patient participation in diabetes self-care. Patient Educ Couns. 2011;85(2):143 7. https://doi.org/10.1016/j.pec.2010.09.025.

20. Heisler M, Bouknight RR, Hayward RA, Smith DM, Kerr EA. The relative importance of physician communication, participatory decision making, and patient understanding in diabetes self-management. J Gen Intern Med. 2002;17(4):243-52.

21. Schillinger D, Piette J, Grumbach K, Wang F, Wilson C, Daher C, et al. Closing the loop: physician communication with diabetic patients who have low health literacy. Arch Intern Med. 2003;163(1):83-90. https:// doi.org/10.1001/archinte.163.1.83

22. Heisler M, Cole I, Weir D, Kerr EA, Hayward RA. Does physician communication influence older patients' diabetes self-management and glycemic control? Results from the Health and Retirement Study (HRS). J Gerontol A Biol Sci Med Sci. 2007;62(12):1435-42.

23. Piette JD, Schillinger D, Potter MB, Heisler M. Dimensions of patientprovider communication and diabetes self-care in an ethnically diverse population. J Gen Intern Med. 2003;18(8):624-33. https://doi.org/10. 1046/j.1525-1497.2003.31968.x

24. White RO, Osborn CY, Gebretsadik T, Kripalani S, Rothman RL. Health literacy, physician trust, and diabetes-related self-care activities in Hispanics with limited resources. J Health Care Poor Underserved 2013;24(4):1756-68. https://doi.org/10.1353/hpu.2013.0177.

25. White RO, Eden S, Wallston KA, Kripalani S, Barto S, Shintani A, et al. Health communication, self-care, and treatment satisfaction among low-income diabetes patients in a public health setting. Patient Educ Couns. 2015;98(2):144-9. https://doi.org/10.1016/j.pec.2014. 10.019

26. Boulware LE, Ephraim PL, Hill-Briggs F, Roter DL, Bone LR, Wolff JL, et al. Hypertension Self-management in Socially Disadvantaged African Americans: the Achieving Blood Pressure Control Together (ACT) Ran domized Comparative Effectiveness Trial. J Gen Intern Med. 2020;35(1):142-52. https://doi.org/10.1007/s11606-019-05396-7.

27. Ephraim PL, Hill-Briggs F, Roter DL, Bone LR, Wolff JL, Lewis-Boyer L, et al. Improving urban African Americans' blood pressure control through multi-level interventions in the Achieving Blood Pressure Control Together (ACT) study: a randomized clinical trial. Contemp Clin Trials. 2014;38(2):370-82. https://doi.org/10.1016/j.cct.2014.06.009.

28. Ameling JM, Ephraim PL, Bone LR, Levine DM, Roter DL, Wolff JL, et al. Adapting hypertension self-management interventions to enhance their sustained effectiveness among urban African Americans. Fam Community Health. 2014;37(2):119-33. https://doi.org/10.1097/FCH. 0000000000000020.

29. Deary IJ, Hepburn DA, MacLeod KM, Frier BM. Partitioning the symptoms of hypoglycaemia using multi-sample confirmatory factor analysis. Diabetologia. 1993;36(8):771-7.

30. Crabtree BF, Miller WL. Doing qualitative research: Sage Publications; 1992.

31. Seed P. DIAGT: Stata module to report summary statistics for diagnostic tests compared to true disease status. 2010.

32. Landis JR, Koch GG. The measurement of observer agreement for categorical data. Biometrics. 1977;33(1):159-74.
33. McHugh ML. Interrater reliability: the kappa statistic. Biochem Med (Zagreb). 2012;22(3):276-82

34. Ginde AA, Blanc PG, Lieberman RM, Camargo CA, Jr. Validation of ICD-9-CM coding algorithm for improved identification of hypoglycemia visits. BMC Endocr Disord. 2008;8:4. https://doi.org/10.1186/14726823-8-4.

35. Kruse RL, Olsberg JE, Oliver DP, Shigaki CL, Vetter-Smith MJ, LeMaster JW. Patient-provider communication about diabetes self-care activities. Fam Med. 2013;45(5):319-22.

36. Rodriguez-Gutierrez R, Salcido-Montenegro A, Singh-Ospina NM, Maraka S, Iniguez-Ariza N, Spencer-Bonilla G, et al. Documentation of hypoglycemia assessment among adults with diabetes during clinical encounters in primary care and endocrinology practices. Endocrine. 2019. https://doi.org/10.1007/s12020-019-02147-w.

37. Parchman ML, Romero RL, Pugh JA. Encounters by patients with type 2 diabetes-complex and demanding: an observational study. Ann Fam Med. 2006;4(1):40-5. https://doi.org/10.1370/afm.422.

38. Harris MI, Cowie CC, Howie LJ. Self-monitoring of blood glucose by adults with diabetes in the United States population. Diabetes Care. 1993;16(8):1116-23. https://doi.org/10.2337/diacare.16.8.1116.

39. Johnson PJ, Ghildayal N, Rockwood T, Everson-Rose SA. Differences in diabetes self-care activities by race/ethnicity and insulin use. Diabetes Educ. 2014;40(6):767-77. https://doi.org/10.1177/ 0145721714552501

40. Vincze G, Barner JC, Lopez D. Factors associated with adherence to self-monitoring of blood glucose among persons with diabetes. Diabetes Educ. 2004;30(1):112-25. https://doi.org/10.1177/ 014572170403000119

41. Martyn-Nemeth P, Schwarz Farabi S, Mihailescu D, Nemeth J, Quinn L. Fear of hypoglycemia in adults with type 1 diabetes: impact of therapeutic advances and strategies for prevention - a review. J Diabetes Complications. 2016;30(1):167-77. https://doi.org/10.1016/j.jdiacomp. 2015.09.003

42. Wild D, von Maltzahn R, Brohan E, Christensen T, Clauson P, GonderFrederick L. A critical review of the literature on fear of hypoglycemia in diabetes: Implications for diabetes management and patient education. Patient Educ Couns. 2007;68(1):10-5. https://doi.org/10.1016/j.pec. 2007.05.003.

43. Fidler C, Elmelund Christensen T, Gillard S. Hypoglycemia: an overview of fear of hypoglycemia, quality-of-life, and impact on costs. J Med Econ. 2011;14(5):646-55. https://doi.org/10.3111/13696998. 2011.610852

44. Zulman DM, Kerr EA, Hofer TP, Heisler M, Zikmund-Fisher BJ. Patient-provider concordance in the prioritization of health conditions among hypertensive diabetes patients. J Gen Intern Med. 2010;25(5):408-14. https://doi.org/10.1007/s11606-009-1232-1.

45. Peek ME, Guinn MT, Gorawara-Bhat R, Odoms-Young A, Wilson SC, Chin MH. How is shared decision-making defined among AfricanAmericans with diabetes? Patient Educ Couns. 2008;72(3):450-8. https://doi.org/10.1016/j.pec.2008.05.018.

46. Grant RW, Adams AS, Bayliss EA, Heisler M. Establishing visit priorities for complex patients: A summary of the literature and conceptual mode to guide innovative interventions. Healthe (Amst). 2013;1(3-4):117-22. https://doi.org/10.1016/j.hjdsi.2013.07.008.

47. Barry CA, Bradley CP, Britten N, Stevenson FA, Barber N. Patients unvoiced agendas in general practice consultations: qualitative study. BMJ. 2000;320(7244):1246-50. https://doi.org/10.1136/bmj.320.7244. 1246.

48. Schoenborn NL, Crossnohere NL, Bridges JFP, Pollack CE, Pilla SJ, Boyd CM. Patient Perceptions of Diabetes Guideline Frameworks for Individualizing Glycemic Targets. JAMA Intern Med. 2019. https://doi. org/10.1001/jamainternmed.2019.3806

49. Lawton J, Rankin D, Elliott J, Heller SR, Rogers HA, De Zoysa N, et al. Experiences, views, and support needs of family members of people with hypoglycemia unawareness: interview study. Diabetes Care. 2014;37(1):109-15. https://doi.org/10.2337/dc13-1154.

50. Lucidi P, Porcellati F, Bolli GB, Fanelli CG. Prevention and Management of Severe Hypoglycemia and Hypoglycemia Unawareness: Incorporating Sensor Technology. Curr Diab Rep. 2018;18(10):83. https://doi. org/10.1007/s11892-018-1065-6.

51. Cox DJ, Gonder-Frederick L, Ritterband L, Patel K, Schächinger $\mathbf{H}$, Fehm-Wolfsdorf G, et al. Blood Glucose Awareness Training: What Is It, Where Is It, and Where Is It Going? 2006;19(1):43-9. https://doi.org/10 2337/diaspect.19.1.43 \%J Diabetes Spectrum.

52. Rondags SM, de Wit M, van Tulder MW, Diamant M, Snoek FJ. HypoAware-a brief and partly web-based psycho-educational group 
intervention for adults with type 1 and insulin-treated type 2 diabetes and problematic hypoglycaemia: design of a cost-effectiveness randomised controlled trial. BMC Endocr Disord. 2015;15:43. https:// doi.org/10.1186/s12902-015-0035-0.

53. Skovlund SE, Lichtenberg TH, Hessler D, Ejskjaer N. Can the Routine Use of Patient-Reported Outcome Measures Improve the Delivery of Person-Centered Diabetes Care? A Review of Recent Developments and a Case Study. Curr Diab Rep. 2019;19(9):84. https://doi.org/10.1007/ s11892-019-1190-X.

54. Jin Y, Li F, Vimalananda VG, Yu H. Automatic Detection of Hypoglycemic Events From the Electronic Health Record Notes of Diabetes Patients: Empirical Study. JMIR Med Inform. 2019;7(4):e14340. https://doi.org/ $10.2196 / 14340$

55. Hazlehurst BL, Lawrence JM, Donahoo WT, Sherwood NE, Kurtz SE, Xu S, et al. Automating assessment of lifestyle counseling in electronic health records. Am J Prev Med. 2014;46(5):457-64. https://doi.org/10. 1016/j.amepre.2014.01.001.
56. Chen J, Lalor J, Liu W, Druhl E, Granillo E, Vimalananda VG, et al. Detecting Hypoglycemia Incidents Reported in Patients' Secure Messages: Using Cost-Sensitive Learning and Oversampling to Reduce Data Imbalance. J Med Internet Res. 2019;21(3):e11990. https://doi.org/10.2196/ 11990

57. Pathak RD, Schroeder EB, Seaquist ER, Zeng C, Lafata JE, Thomas A, et al. Severe Hypoglycemia Requiring Medical Intervention in a Large Cohort of Adults With Diabetes Receiving Care in U.S. Integrated Health Care Delivery Systems: 2005-2011. Diabetes Care. 2016;39(3):363-70. https://doi.org/10.2337/dc15-0858.

58. Gandhi TK, Weingart SN, Borus J, Seger AC, Peterson J, Burdick E, et al. Adverse drug events in ambulatory care. N Engl J Med. 2003;348(16):1556-64. https://doi.org/10.1056/NEJMsa020703.

Publisher's Note: Springer Nature remains neutral with regard to jurisdictional claims in published maps and institutional affiliations. 